\title{
ASPECTOS REPRODUTIVOS DO PEIXE-ZEBRA, Danio rerio, EXPOSTO A DOSES SUBLETAIS DE DELTAMETRINA
}

\section{(Reproductive aspects of zebrafish, Danio rerio, exposed to sublethal doses of deltamethrin)}

\author{
TRAMUJAS, F.F.'; FÁVARO, L.F. ${ }^{2}$; PAUKA, L.M. ${ }^{3}$; SILVA DE ASSIS, H.C. ${ }^{3}$ \\ ${ }^{1}$ Programa de Pós-graduação em Ciências Veterinárias, UFPR, Curitiba, Pr; \\ ${ }^{2}$ Departamento de Biologia Celular, UFPR, Curitiba, Pr; \\ ${ }^{3}$ Departamento de Farmacologia, UFPR, Curitiba, Pr.
}

\begin{abstract}
RESUMO - A deltametrina está listada pela Agência de Proteção Ambiental dos Estados Unidos (USEPA) como possível desregulador endócrino, podendo, portanto, interferir no sistema reprodutivo. É um piretróide sintético, com ação inseticida, toxicidade relativamente baixa para mamíferos e persistência limitada no meio ambiente, mas de alta toxicidade para organismos aquáticos. É também empregada nas medicinas humana e veterinária para profilaxia e tratamento de doenças parasitárias. O objetivo deste estudo foi avaliar possíveis alterações na reprodução do peixe zebra (Danio rerio) seguindo o protocolo da USEPA (2002). Os peixes foram expostos a concentrações subletais de deltametrina $(6 \mu \mathrm{g} / \mathrm{L}$ e 10 $\mu \mathrm{g} / \mathrm{L}$ ) e à acetona (solvente), durante 14 dias. Parâmetros como número de ovos, eclosão, índice gônado-somático e histologia de gônadas foram avaliados. Não foi possível observar nenhuma diferença significativa dos parâmetros avaliados entre os grupos, concluindo-se que a deltametrina não alterou a reprodução da espécie estudada. Neste trabalho a progênie não foi avaliada, pois não fazia parte do protocolo proposto. Porém, as substâncias desreguladoras endócrinas podem atuar afetando o sistema neuroendócrino reprodutivo e estas alterações podem apresentar-se tanto nos progenitores como na progênie em diferentes etapas do desenvolvimento.
\end{abstract}

Palavras-chave: piretróide, Danio rerio, desregulador endócrino, reprodução, deltametrina.

ABSTRACT - The deltamethrin is listed by the Environmental Protection Agency of the United States (USEPA) as a possible endocrine disruptor, being able to interfere in the reproductive system. It is a synthetic pyrethroid, with potent insecticide action, relatively low toxicity in mammals and limited persistence in the environment, but high toxic to aquatic organisms. It is also used in the human and veterinary medicines for prophylaxis and treatment of parasitic diseases. The aim of this study was to evaluate possible endocrine alterations in the reproduction of the zebrafish (Danio rerio) following the protocol of USEPA (2002). The fish were exposed to sublethal concentrations of deltamethrin $(6 \mu \mathrm{g} / \mathrm{L}$ and $10 \mu \mathrm{g} / \mathrm{L}$ of the technical deltamethrin) and acetone, used as solvent, during 14 days. Parameters as number of eggs, hatching, size and histology of the gonads were evaluated. It was not observed any significant difference of the evaluated parameters among the groups. The deltamethrin didn't alter the reproduction of the zebrafish. In the present study the progeny was not evaluated, because was not included in the used protocol. However, endocrine disruptor substances can affect the neuroendocrine reproductive system and the alterations can appear in the progenitors or in the progeny in different stages of the development.

Key-words: Deltamethrin, Danio rerio, endocrine disruptors, reproduction.

\section{Introdução}

A utilização de compostos químicos como os pesticidas (incluindo inseticidas, herbicidas e fungicidas) para defender as lavouras de insetos, ervas daninhas e fungos sem o conhecimento ou avaliação dos riscos para o ecossistema constituí uma potencial ameaça para a saúde de pessoas, animais e vegetais (BONACELLA, 1990). Em 1962, a naturalista RACHEL CARSON alertou o mundo para os perigos do emprego de pesticidas na agricultura por causa dos efeitos desses compostos na reprodução das aves.

Entre outros pesticidas, a deltametrina está listada como desregulador endócrino (GRAY e OTSBY, 1998), podendo interferir no sistema reprodutivo. Segundo a USEPA, 2002 os agentes químicos capazes de interferir no sistema endócrino são correntemente designados de desreguladores endócrinos. A deltametrina é um piretróide desenvolvido a partir de modificações químicas na estrutura das piretrinas naturais encontradas nos extratos das flores secas do crisântemo Chrysanthemum cinerariaefolium e C. cocineum.

Dados encontrados na literatura (WHO, 1990, BARLOW et al., 2001, REDDY e PHILIP, 1994, MIAN e MULLA, 1992) indicam a deltametrina como uma substância com potencial de desregulador do sistema 
Aspectos reprodutivos do peixe-zebra, Danio rerio, exposto a doses subletais de deltametrina

neuroendócrino, porém não há estudos que avaliem seu efeito na reprodução do peixe-zebra. A referida espécie tem sido utilizada como modelo experimental em vários estudos farmacológicos e toxicológicos (HUUSKONEN, 2005, KUSTER, 2005). Neste estudo foi utilizada por apresentarse como um organismo teste de fácil adaptação em laboratório, por ter uma reprodução contínua e com número de ovos suficiente para os testes propostos.

O objetivo do trabalho foi avaliar os efeitos de doses subletais de deltametrina no processo reprodutivo do peixe-zebra Danio rerio, utilizando o protocolo de 14 dias de exposição da Agência de Proteção Ambiental dos Estados Unidos para estudos de substâncias químicas com capacidade de desregular o sistema endócrino.

\section{Material e Método}

Foram utilizados 16 aquários (quatro réplicas de cada grupo) de 16 litros, com água filtrada e desclorada, aeração constante, temperatura $25^{\circ} \mathrm{C}$ e $\mathrm{pH}$ 6,5 \pm 0,5 e fotoperíodo de 16/8 dia/noite, de acordo com o protocolo da USEPA (2002).

Em cada aquário foram introduzidos seis exemplares adultos de peixe-zebra, sendo quatro fêmeas e dois machos. Os aquários continham uma rede interna para proteção dos ovos que se depositavam no fundo, evitando com que os indivíduos adultos se alimentassem dos mesmos. Os peixes foram alimentados com ração comercial duas vezes ao dia.

A deltametrina técnica com $98,8 \%$ de pureza, fornecida pela Aventis CropScience Brasil Ltda, foi dissolvida em acetona.

Os peixes foram expostos a concentrações subletais de $6 \mu \mathrm{g} / \mathrm{L}$ e $10 \mu \mathrm{g} / \mathrm{L}$ de deltametrina, concentrações obtidas em um pré-teste desenvolvido com bases no estudo de VIRAN et al. (2003), com quatro réplicas para cada concentração e para dois tipos de controle, um realizado com água e o outro com acetona, a qual serviu como solvente para a deltametrina.

O ensaio foi semiestático, ou seja, a cada 24 horas foram retirados 4 litros de água dos aquários. Essa mesma quantidade foi reposta já com a substância teste nas respectivas concentrações de cada aquário.

O tempo de duração do experimento foi de 14 dias. Os peixes foram avaliados diariamente durante 0 período, observando-se sobrevivência e comportamento, bem como alterações externas como hemorragia e descoloração. Comportamentos anormais foram anotados, como hiperventilação, falta de coordenação de natação e alteração na ingestão de alimentos.

A coleta dos ovos foi realizada por meio de sifonagem, sendo os mesmos retirados juntamente com possíveis deposições de alimentos e excretas, segundo protocolo de WESTERFIELD (2000). O líquido retirado foi colocado em pratos pretos e, com o auxílio de uma lente de aumento, focos de luz e uma pipeta, os ovos foram sendo pipetados e contados. Os ovos contados foram colocados em recipientes menores, lavados com água em um filtro e colocados em recipientes denominados neste trabalho de maternidades. As maternidades foram mantidas em um aquário maior, todas separadas e identificadas por concentrações e dias, com temperatura por volta de $27^{\circ} \mathrm{C}$. Para cada aquário havia cinco maternidades onde os ovos permaneceram por 72 horas. Após este período, o número de alevinos eclodidos foi contado.

No décimo quarto dia depois da última coleta e contagem dos ovos, uma fêmea e um macho de cada aquário foram sacrificados e pesados. As gônadas foram retiradas e pesadas para cálculo do índice gônado-somático (IGS), obtido pela fórmula: IGS = (peso da gônada/peso total) x 100 .

Posteriormente, as gônadas foram fixadas em solução de Alfac por 16 horas seguindo-se os procedimentos histológicos de rotina para inclusão em parafina. As laminas foram coradas com Hematoxilina-Eosina e analisadas em microscópio de luz para descrição morfológica das diferentes fases de desenvolvimento das células das linhagens gaméticas feminina e masculina, de acordo com VAZZOLER (1996).

As variáveis obedeceram à distribuição normal e foram comparadas por meio de análise de variância (ANOVA), seguido do pós-teste de Bonferroni, para comparação entre os grupos, com nível de significância $p<0,05$. Os resultados foram expressos como média \pm erro padrão da média.

\section{Resultados}

Os indivíduos dos grupos controle (água e acetona) e os submetidos as diferentes concentrações de deltametrina mantiveram-se vivos durante os 14 dias do experimento, não apresentando alterações externas como hemorragia ou descoloração. Também não se observou sinais gerais de intoxicação, como hiperventilação, alteração na natação e na alimentação. As análises não evidenciaram diferenças significativas entre os grupos controle e contaminado em relação ao número total de ovos coletados, ao número de ovos eclodidos e ao IGS para sexos separados durante 0 período de estudo (TABELA1). 
TABELA 1 -MÉDIA E ERRO PADRÃO DA CONTAGEM DO NÚMERO DE OVOS, NÚMERO DE OVOS ECLODIDOS, ÍNDICE GÔNADO-SOMÁTICO DAS FÊMEAS E DOS MACHOS DE Danio rerio.

\begin{tabular}{ccccc}
\hline $\begin{array}{c}\text { Concentração de } \\
\text { Deltametrina }(\mu \mathrm{g} / \mathrm{l})\end{array}$ & $\begin{array}{c}\text { Número de } \\
\text { ovos }\end{array}$ & $\begin{array}{c}\text { Número de ovos } \\
\text { eclodidos }\end{array}$ & $\begin{array}{l}\text { Índice gônado- } \\
\text { somático das } \\
\text { fêmeas }(\%)\end{array}$ & $\begin{array}{l}\text { Índice gônado- } \\
\text { somático dos } \\
\text { machos (\%) }\end{array}$ \\
\hline água & $2.195 \pm 381$ & $1.077 \pm 144$ & $8,52 \pm 1,01$ & $1,63 \pm 0,23$ \\
acetona & $2.895 \pm 189$ & $783 \pm 45$ & $7,98 \pm 0,73$ & $1,87 \pm 0,36$ \\
6 & $1.727 \pm 214$ & $827 \pm 201$ & $9,18 \pm 0,32$ & $1,56 \pm 0,33$ \\
10 & $1.562 \pm 306$ & $840 \pm 253$ & $7,90 \pm 0,99$ & $1,60 \pm 0,08$ \\
\hline
\end{tabular}

A morfologia das gônadas das fêmeas caracterizou as cinco fases de desenvolvimento dos folículos ovarianos (ovogênese) para Danio rerio. Os folículos atrésicos e vazios não foram considerados como fase de desenvolvimento no processo de ovogênese, e sim estruturas derivadas do referido processo.

Os cortes histológicos das gônadas mostraram o mesmo padrão característico de ovários e testículos verificados para a maioria dos teleósteos. Através da análise histológica das gônadas dos indivíduos do grupo contaminado foi possível observar que o desenvolvimento dos folículos ovarianos, considerando o ovócito e suas inclusões citoplasmáticas (vesículas citoplasmáticas e grânulos de vitelo), bem como suas membranas envoltórias (células foliculares e membrana vitelina) e a afinidade por corantes, apresentou as mesmas características do grupo controle.

Folículos vazios foram observados nos cortes histológicos de ovários dos grupos controle e contaminado, indicando que o grau de contaminação a que os indivíduos foram expostos não interferiu na eliminação dos ovócitos (FIGURAS 1 e 2).

\section{FIGURA 1 - FOTOMICROGRAFIA DE GÔNADA DE FÊMEA DE Danio rerio DO GRUPO CONTROLE.}

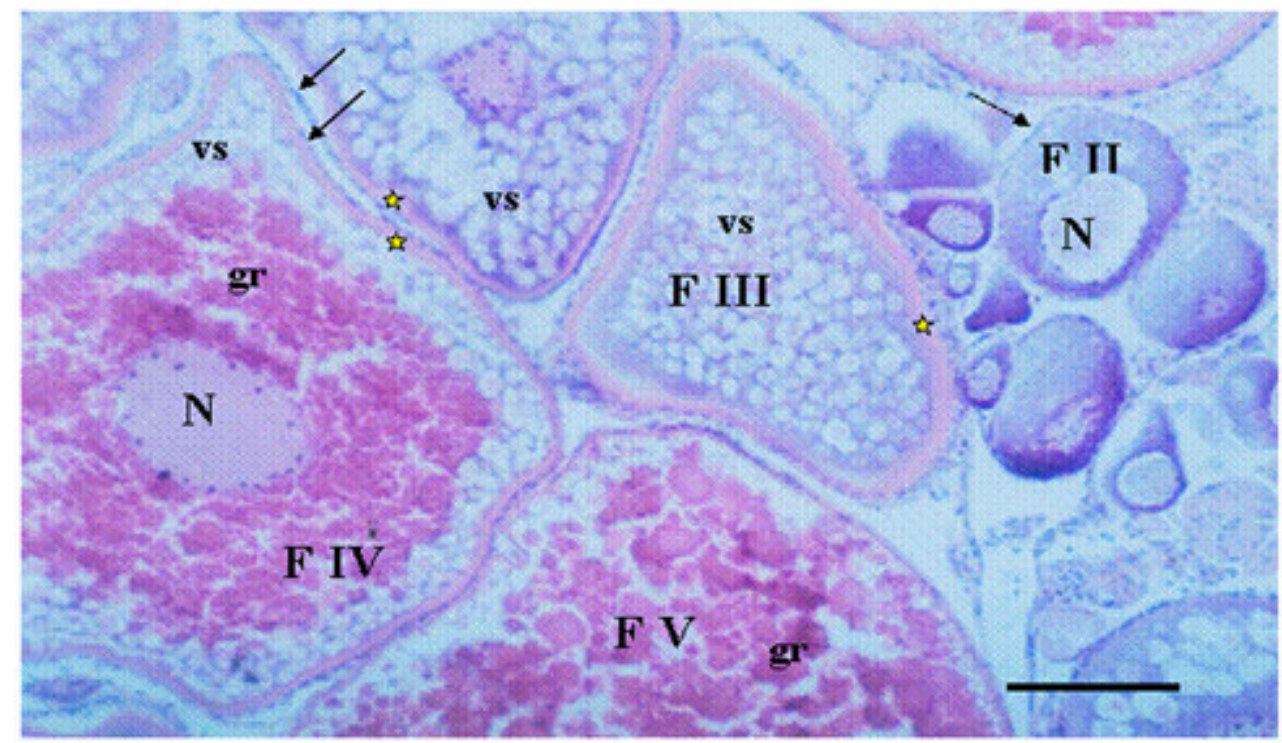

NOTA: Folículos ovarianos nas: Fase II (surgimento de células foliculares); Fase III (surgimento da membrana vitalina e de vesículas citoplasmáticas); Fase IV (aparecimento de grânulos de vitelos); Fase V (citoplasma repleto de grânulos de vitelo). FII, FIII, FIV, FV, respectivamente, núcleos (N), vesículas citoplasmáticas (vs), grânulos de vitelo (gr), células foliculares $(\hat{\uparrow})$, membrana vitelina $(\hat{\sim})$. Escala $=90 \mu \mathrm{m}$. Coloração H.E. 
Aspectos reprodutivos do peixe-zebra, Danio rerio, exposto a doses subletais de deltametrina

FIGURA 2 - FOTOMICROGRAFIA DE GÔNADA DE FÊMEA DE Danio rerio EXPOSTA À CONCENTRAÇÃO DE 10 g/l.

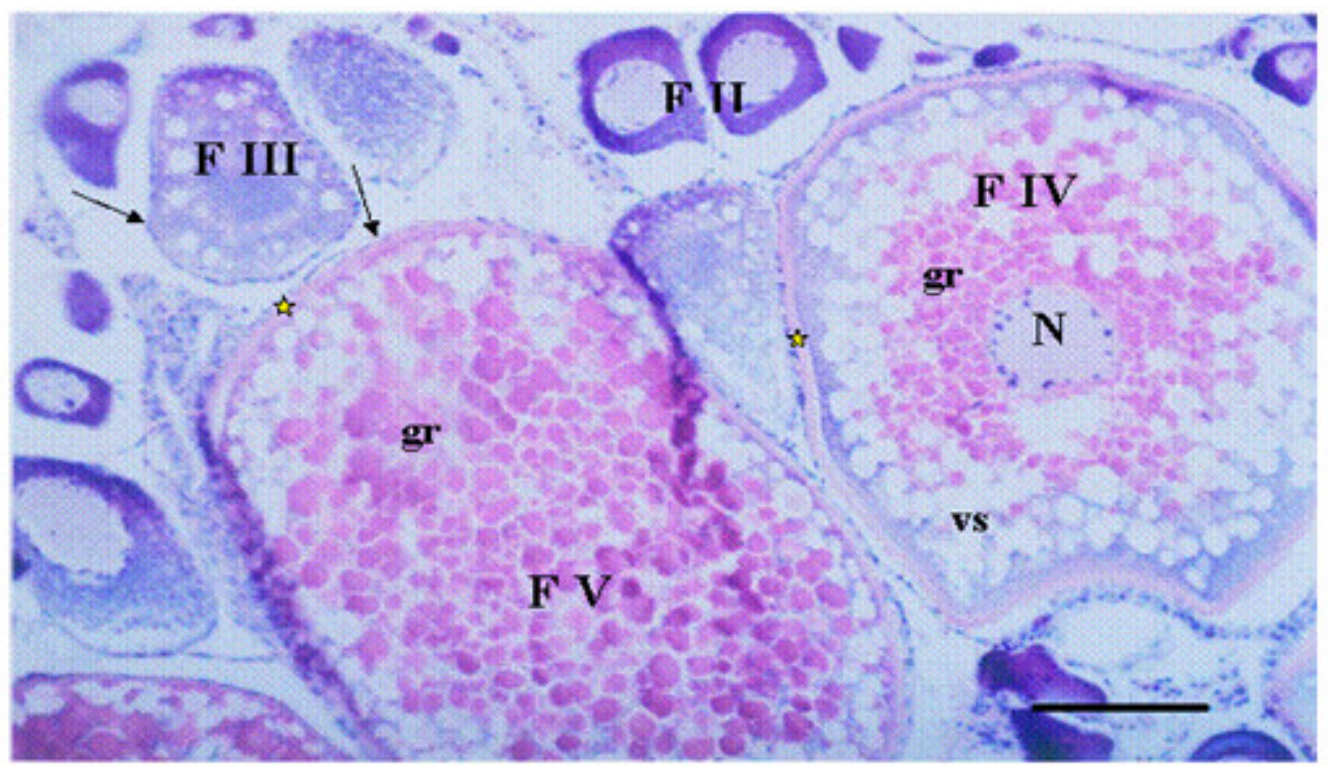

NOTA: Folículos ovarianos nas fases II, III, IV e V. FII, FIII, FIV e FV, respectivamente, núcleos (N), vesículas citoplasmáticas

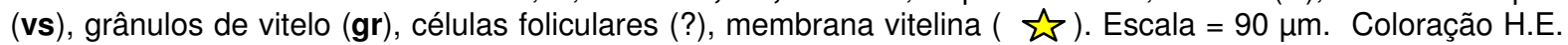

A análise histológica das gônadas masculinas (FIGURAS 3 e 4), dos grupos expostos nas duas concentrações de deltametrina, revelou ausência de alteração nas células da linhagem espermática quando comparadas com os grupos controle, indicando que as concentrações utilizadas não causaram alterações microscópicas entre os grupos.

FIGURA 3 - FOTOMICROGRAFIA DE GÔNADA DE Danio rerio MACHO, DO GRUPO CONTROLE.

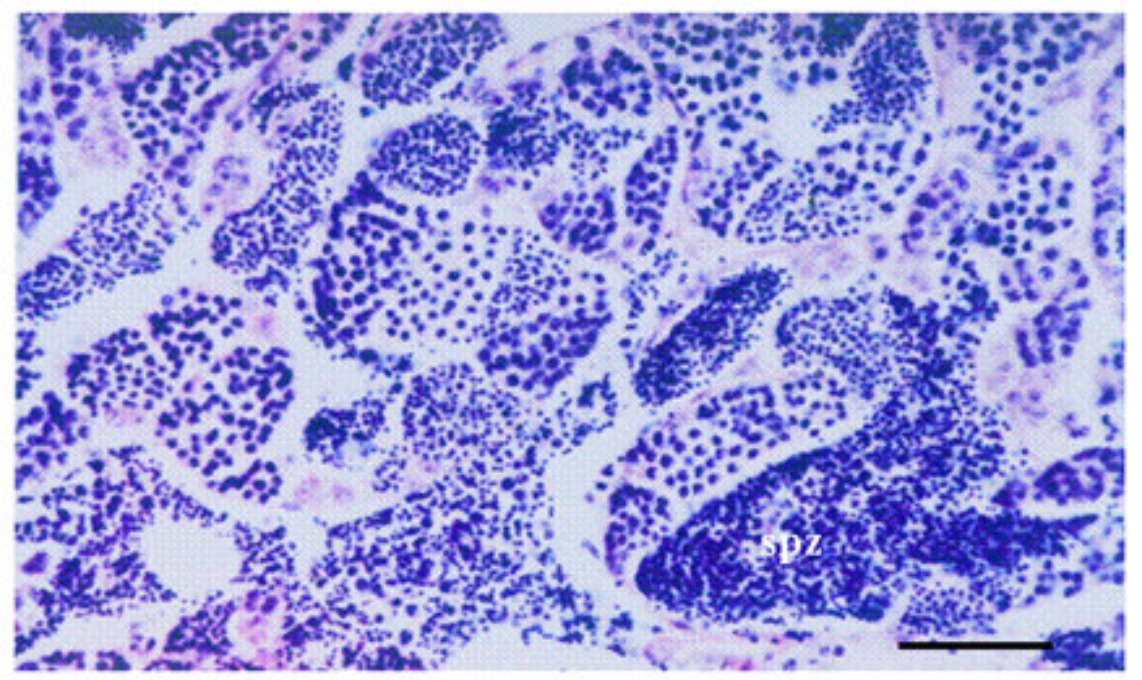

NOTA: Testículo com diferentes células da linhagem gamética. Espermatozóide (spz). Escala: $45 \mu \mathrm{m}$. Coloração H.E. 


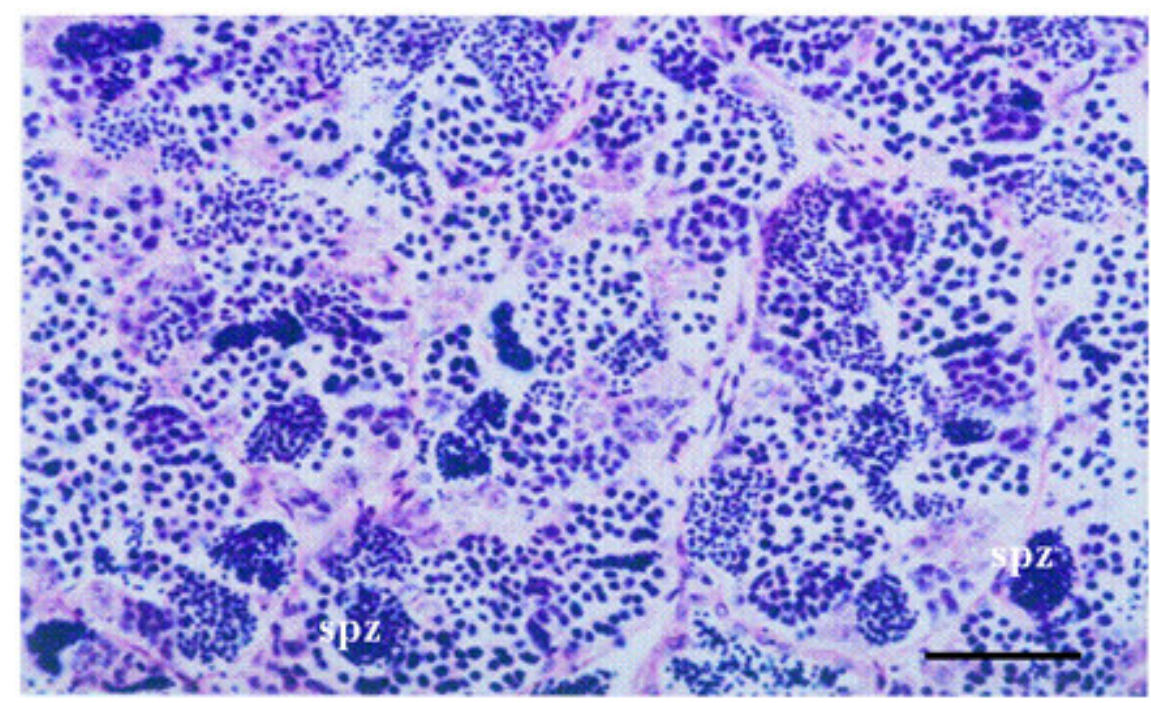

NOTA: Testículo com diferentes células da linhagem gamética. Espermatozóide (spz). Escala: 45 $\mu$ m. Coloração H.E.

\section{Discussão}

Recentemente, grande atenção tem sido dada aos possíveis efeitos adversos decorrentes da exposição de animais aquáticos a agentes químicos durante as fases pré e perinatal. A exposição a pesticidas e outras substâncias tóxicas durante essas fases, pode alterar componentes do sistema nervoso central e reprodutivo sem comprometer o crescimento e a viabilidade dos descendentes, mas causar alterações funcionais que se tornam aparentes posteriormente, na idade adulta (NEUBERT e CHAHOUD, 1995; FAQI, 1998; GRAY e OTSBY, 1998). Os resultados obtidos no presente estudo indicam que não houve efeito, nos parâmetros avaliados, da deltametrina nas concentrações utilizadas. ANDRADE et al. (2002) estudando a deltametrina em ratas, verificaram que durante a prenhez, o tamanho da ninhada, a razão sexual dos filhotes e os índices de parto, nascimento e desmame também não foram afetados nas doses testadas. Porém, mostraram que houve redução no peso absoluto dos testículos e epidídimo e produção espermática diária na progênie quando comparados com o controle.

$\mathrm{Na}$ presente pesquisa foi seguido o protocolo da USEPA de 14 dias para testes de substâncias com potencial de desregular o sistema endócrino, o qual não inclui teste de progênie. Assim, não se descarta a hipótese de que os descendentes, na fase adulta, possam apresentar alguma alteração reprodutiva.

No que se refere ao índice gônado-somático dos animais expostos ou não à deltametrina ele variou de acordo com os dados na literatura. Conforme USEPA (2002) o IGS de Danio rerio varia de 8 a 13\% para fêmeas e de 1 a $2 \%$ para machos. No estudo, todos os índices calculados, encontravam-se dentro dessas médias propostas, tanto das fêmeas quanto dos machos.

Apesar de neste estudo não terem sido observadas alterações nos parâmetros avaliados, a deltametrina pode ser responsável por alterações em outros órgãos e em outras vias de exposição. Muitos estudos revelam que a deltametrina é um pesticida piretróide bem caracterizado como um agente neurotóxico (WHO, 1990; REDDY e PHILIP, 1994; GRAY e OTSBY, 1998).

NICARETA (2004) estudou os efeitos de doses subletais da deltametrina em peixes Ancistrus multispinnis (cascudos) e observou inibição da atividade da $\mathrm{Na}^{+} \mathrm{K}^{+}$-ATPase das brânquias, coração e esôfago e indução da quantidade total do citocromo P450, bem como da atividade da etoxiresorufina-O-deetilase. KAZETO et al. (2004) estudaram alterações no citocromo $\mathrm{P} 450$ em relação ao sistema reprodutivo de Danio rerio. O citocromo P450 aromatase (CYP19) é a enzima estrogênica fundamental para conversão de andrógeno em estrógeno, com uma importante atuação na fase crítica de diferenciação sexual e no ciclo reprodutivo dos vertebrados adultos. No estudo, foi observado que o composto estrogênico nonilfenol e o etinilestradiol (EE) induziram a expressão do CPY19A2, em doses dependentes. A exposição ao benzo[a]pireno (BaP), que é um contaminante ambiental, também aumentou significativamente a transcrição do CYP19A2. Em contrapartida, o CPY19A1 foi resistente ao tratamento com substâncias com potencial de desregulador endócrino, mas quando exposto a etinilestradiol (EE) em altas concentrações a expressão diminuiu. Os dados sugerem que muitas classes de desreguladores endócrinos podem afetar o eixo hipotálamo-hipófise-gônadas em peixes através de uma diferente transcrição do gene CYP19. 
Aspectos reprodutivos do peixe-zebra, Danio rerio, exposto a doses subletais de deltametrina

Mais estudos sobre as substâncias propostas como desreguladoras endócrinas e suas ações no sistema neuroendócrinoreprodutivo são necessários. Primeiramente, estudos em laboratório devem ser realizados com uma única substância para elucidar o mecanismo de ação e os efeitos da mesma, porém estudos com misturas de substâncias devem também ser processados.

\section{Conclusões}

A partir dos resultados obtidos observou-se que utilizando um único protocolo não se pode afirmar que a deltametrina não tem efeito no processo reprodutivo. No caso em que a deltametrina tenha propriedades de um agente desregulador endócrino sugere-se a utilização de mais de um protocolo já validado por agências internacionais, ou a implementação de novos protocolos para estudos de toxicologia reprodutiva. Esses estudos são de fundamental importância na avaliação dos riscos que estes contaminantes ambientais apresentam ao meio ambiente e a saúde pública e animal.

\section{Referências}

ANDRADE, A.J.M.; SANTANA, G.M.; ARAÚJO, S.L.; OHI, M.; DALSENTER, P.R. Reproductive effects of deltamethrin on male offspring of rats exposed during pregnancy and lactation. Regulatory Toxicology and Pharmacology, 36 310-317 2002.

BARLOW, S.M.; SULLIVAN, F.M.; LINES, J. Risk assessment of the use of deltamethrin on bednets for the prevention of malaria. Food and Chemical Toxicology, v.39, p.407-442, 2001.

BONACELLA, P. H. A poluição das águas. Coleção Desafio. Moderna- SP, p. 28-30,1990.

CARSON, R. Pimavera Silenciosa. Ed. Melhoramento, São Paulo, p.305, 1962.

FAQI, A.S., Dalsenter, P.R., Merker, H.J., Chahoud, I. Reproductive toxicity and tissue concentrations of low doses of 2,3,7,8-tetrachlorodibenzo-p-dioxin in male offspring rats exposed throughout pregnancy and lactation. Toxicology and Applied Pharmacology, v.150, p. 383-392, 1998.

GRAY Jr, L.E.; OTSBY, J. Effects of pesticides and toxic substances on behavioral and morphological reproductive development: endocrine versus nonendocrine mechanisms. Toxicology and Industrial Health, v.14, n.1/2, p. 159-184, 1998.
HUUSKONEN, H. New models and molecular markers in evaluation of developmental toxicity. Toxicology and Applied Pharmacology, v.205, p. 495-500, 2005

KAZETO, Y.; PLACE, A.R.; TRANT, J.M. Effects of endocrine disrupting chemicals on the expression of CYP19 genes in zebrafish (Danio rerio) juveniles. Aquatic Toxicology, v.69, p. 25-34, 2004.

KUSTER, E. Cholin-and carboxylesterase activities in developing zebrafish embryos (Danio rerio) and their potential use for insecticide hazard assessment. Aquatic Toxicology, v. 75, p. 76-85, 2005.

MIAN, L.S.; MULLA, M.S. Effects of pyrethroid insecticides on nontarget invertebrates in aquatic ecosystems. Journal of Agricultural Entomology, v.9, p.73-98, 1992.

NEUBERT, D.; CHAHOUD, I. Possible consequences of pre- or early postnatal exposure to substances with estrogenic or androgenic properties. Endocrinology Chemical Environmental, v.3, p.24-52, 1995.

NICARETA, L. Biomarcadores para a detecção de efeitos subletais causados pela deltametrina em Ancistrus multispinis. Curitiba, 2004. 70 p. Dissertação (Mestrado em Farmacologia), Curso de Farmacologia, Universidade Federal do Paraná.

REDDY, P.M.; PHILIP, G.H. In vivo inhibition of AchE and ATPase activities in the tissue of freshwater fish, Cyprimus carpio exposed to technical grade cypermethrin. Bulletin of Environmental Contamination and Toxicology, v.52, p.619$626,1994$.

USEPA (ENVIRONMENTAL PROTECTION AGENCY). EPA/68-W-01-023: Fish screening assays for endocrine disruption, Ohio, 2002.

VASSOLER, A.E.A.M. Biologia da reprodução de peixes teleósteos: teoria e prática. Maringá, EDUEM, 1996, 169p.

VIRAN, R.; ERKOÇ, F.U.; POLAT,H.; KOÇAK,O. Investigation of acute toxicity of deltamethrin on guppies (Poecilia reticulata). Ecotoxicology and Environmental Safety. V. 55, p. 82-85, 2003.

WESTERFIELD, M. The Zebrafish Book: Guide for the Laboratory Use of Zebrafish (Danio rerio), University of Oregon, $4^{\text {th }} \mathrm{Ed}$,Eugene, 2000. Disponível em: http:/ /zfin.org/zf_info/zfbook/zfbk.html. Acesso: 20 jan. 2003.

WHO - WORLD HEALTH ORGANIZATION. Deltamethrin, environmental health criteria, 97. Geneva: World health organization. IPCS, 1990.
Recebido para publicação: Aprovado:
$29 / 03 / 2006$

$30 / 062066$ 